Hughes, ${ }^{1}$ develops relations which suggest that the elements may be constituted analogously to the organic radicals. Still a third paper, by Henry Wilde, also deserves attention. ${ }^{2}$

International Atomic Weights.-The report of the smaller International Committee for $1903^{3}$ has been sharply criticized by Ostwald. ${ }^{*}$ To this criticism, which related mainly to the standard of values, Seubert published a reply. ${ }^{5}$ The subject of a standard has also been discussed by Winkler, ${ }^{6}$ whose paper called forth a rejoinder by Landolt and Ostwald. In a still later note, Winkler answers his critics. ${ }^{8}$ For the purposes of this report, these references to literature are sufficient.

\title{
THE CHEMICAL COMPOSITION OF COOKED VEGETABLE FOODS.
}

By Miss katharine I. Williams.

Recelved December 9, 1903

THE investigations described in the following pages were undertaken at the suggestion of Sir William Ramsay; during the course of the work I have received much kind assistance from Dr. S. Young, in the way of advice as to working-details. Most of the previous work published on this subject deals with anal$y$ sis of raw foods; the main object of this investigation was to gain information regarding the composition of foods as served at table.

The fresh, green vegetables were bought when in full season, the leeks in April, the rhubarb in March, the broccoli and Brussels sprouts in January, asparagus in the middle of May, while the green artichokes were purchased in June.

General Preparation of the Samples Used.-The chief consideration was to obtain a sample of each vegetable food as it would be served at table, therefore, in the case of broccoli, Brussels sprouts, rhubarb, leeks, asparagus, and green artichokes the usual

1 Chem. News, 88, 298.

2 Mem. Manchester Lit. Phil. Soc., 48 , I.

3 This Journal, 25, (1903)

4 Ztschr. phys. Chem. 42,637.

5 Ztschr. anorg. Chem., 35, 45.

- Chem. Zig., 27, 918.

7 Ber. d. chem. Ges., 36, 3759.

8 lbid, 36, 4299 . 
refuse in the way of stems and leaves was removed before cooking. DETAILS AS TO COOKING.

Broccoli.-This vegetable was well soaked in cold water, then removed and placed in an uncovered sauce-pan containing boiling water, being briskly boiled for about fifteen minutes, then removed and allowed to drain on a sieve. No salt or sugar was added during the process.

Brussels Sprouts.-When ready for cooking, the sprouts were put into plenty of boiling water, and treated in the same way as the broccoli. No pepper or salt was added.

Asparagus.-The ordinary small variety was used, the sticks being first washed and scraped, then tied into bundles of twelve and the white ends cut even. The bundles were placed in an open sauce-pan containing hot water, which was not allowed to cover the heads; the boiling was continued for fifteen minutes, the bundles were then removed from the pan and the excess of water drained off on a sieve. No salt or vinegar was used in the cooking, and the hard portion of stems was removed before the estimation of water.

Green Artichokes. - These were placed in boiling water in an uncovered sauce-pan, and boiled for two hours. No salt or potash was added to the water. When cooked, the heads were allowed to drain on a sieve; all the leaves and fibrous portions were removed and only the fleshy receptacle of the flowers was analyzed.

Leeks.-This vegetable was cooked in a similar way to the green artichokes, in boiling water, without the addition of salt.

Oatmeal.-The variety used was coarse Scotch; two tablespoonfuls were gently added to a pint of boiling water, well stirred all the time, then gently boiled for half an hour and stirred now and again ; no salt was added. In the case of the milk porridge, two tablespoonfuls of the oatmeal were well stirred in a little cold water, the mixture was allowed to clear and the water poured off; $1 / 2$ pint of milk and $1 / 2$ pint of water were added to the oatmeal and the whole briskly boiled for half an hour.

Dried Peas.-They were first soaked for several hours in cold water, then tied in a cloth and put into a sauce-pan containing cold water, but no salt or sugar; they were allowed to simmer 
for three hours until tender, when they were ready to be drained on a colander.

Tapioca (Flake).-Two ounces were first soaked in a pint of water for twenty minutes, then put on the fire in a stew-pan; the mixture was well stirred until it boiled; the pan was then drawn to the side of the fire and allowed to simmer until the tapioca was soft.

Lentils.-The red variety was used. The lentils were well soaked for about three hours in cold water, when they were put into a sauce-pan with plenty of cold water and briskly boiled for half an hour, then allowed to simmer until soft, when they were drained on a colander.

Rice.-The sample used was Carolina. The rice was first washed and then placed on a sieve to drain, when it was ready to be shaken into boiling water; it was then briskly boiled, while occasionally stirred, until it was quite tender, and ready to be drained on a colander.

Macaroni.-Prepared in Genoa. The first process was to break the sticks up into short lengths, ready to be plunged into boiling water; the boiling was kept up for about half an hour, when the process was arrested by adding cold water, and the macaroni was drained over a colander. No salt was used in the cooking.

Rhubarb.-The pink variety was the one used. The leaf stems were cut into short lengths, and the stewing was done without the addition of sugar.

Baked Beans.-The variety used was the Thubber Brand, New York.

I'ctit Pois.-The tin was marked "Victor Fertrais, a bel abord sur Sevre, Nantes." The contents of the tin werc drained on a sieve; the filtrate consisted of $269 \mathrm{cc}$. liquid, which, on evaporation, left I I.54 grams of solid, 3.65 grams of which were protein.

All these vegetable foods were boiled in undistilled water, as supplied by the Bristol Water Company, which shows about $26^{\circ}$ of hardness, chiefly due to calcium carbonate.

livery sample was weighed before and after cooking, as is shown in Table I; also the percentages of refuse in the raw and cooked conditions are given, as well as the percentage of edible matter, and the price per pound of the raw material. 
TABLE I.

As purchased.

Brussels sprouts …. $2^{1 / 2}$

Rice .............. 4

Rhubarb.......... $2^{1 / 4}$

Lentils............ $2^{1 / 2}$

Oatmeal (water) $\cdots 2^{1 / \frac{1}{2}}$

Oatmeal (milk) .... ...

Asparagus …...... $9^{1 / 2}$

Peas............. $2^{1 / 2}$

Tapioca............ 5

Artichokes ......... $2^{1 / 2}$

Petit pois $\ldots \ldots \ldots, 5^{1 / 4}$

Baked beans ........ $5^{1 / 4}$

Leeks............ $\mathrm{I}^{1 / 2}$

Macaroni ......... \& 8

Broccoli ............ ${ }^{3}{ }^{3 / 4}$

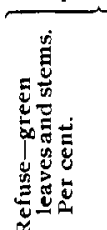

6.34

....

19.55

....

.....

....

35.13

....

....

72.70

77.30
.70

... 100.00

... 100.00

$74.69 \quad 25.3 \mathrm{I}$

.... $100 . \infty$

$67.97 \quad 32.03$
As served at table.

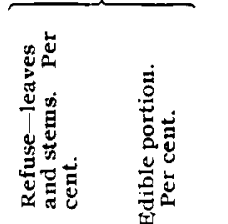

.... 100.00

.... 100.00

.... 100.00
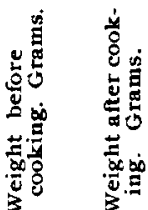

IOO

I21.0

IOO

418.0

... I 100.00

IOO

....

.... 100.00

I $\infty$

238.4

280.3

... $100.00 \quad 100 \quad 254.6$

$34.18 \quad 65.82 \quad$ I00 $\quad 56.9$

....

100.00

$10 \mathrm{C}$

2 I0.I

… 100.00

100

430.3

$\begin{array}{llll}68.7 \mathrm{I} & 3 \mathrm{I} .29 & \mathrm{I} 00 & 336 . \mathrm{I}\end{array}$

.... 100.00

.... 100.00

... 100.00

100

$\cdots$

.... 100.00

100

187.5

252.4

... I $100 . \infty \quad 100$

ANALYSIS OF THE EDIBLE PORTION.

Determination of Water.-Every sample of the green, cooked vegetables, and also of the cooked cereals, was broken up into small pieces, the surface water being removed before the process of drying was commenced. A small portion, from 20-50 grams of the vegetable substance, was weighed in an evaporating dish, and heated from twelve to twenty-four hours, first in a steambath and then in an air-bath at a temperature not exceeding $110^{\circ}$. When the sample was fairly firm it was allowed to cool in a desiccator, weighed again, and reduced to powcler in a coffee-mill. A portion of the powder was again weighed, placed in the airbath and kept at a temperature not exceeding $110^{\circ}$ until the weight remained constant; from these results the percentage of water vas calculated. Two estimations were made in every case.

Fat.-The fat and coloring-matters, when present, were extracted from the powdered foods by ether. From 4 to 6 grams were placed in a wide glass tube, the narrower and lower end of which was closed with a plug of cotton wool, and passed through a cork into a small flask of about Ioo cc. capacity, con- 
taining ether; the upper end of the tube was connected with a reflex Liebig condenser. The flask was heated by a waterbath; the ethereal vapors passing through the cotton wool to the powdered substance were condensed in the conclenser, and the ether dissolved the oil as it passed back through the tube into the cooled flask; the process was repeated until a drop on evaporation left no residue; when all the soluble matter had been extracted, the ether was distilled off and the residue weighed.

Woody Fiber.-The method used in this portion of the work was that described by Dr. H. W. Wiley in "Principles and Practice of Agricultural Chemistry," Vol. III, p. 303. About 2 grams of the residue from the determination of fat was used in each case, and was boiled first with $200 \mathrm{cc}$. of I.25 per cent. sulphuric acid; after filtration, the residue was washed with boiling water until the washings were no longer acid. It was then boiled with $200 \mathrm{cc}$. of I.I25 per cent. solution of sodium hydroxide, nearly free from sodium carbonate, next filtered into a Gooch crucible, washed with boiling water, then dried at $110^{\circ}$, weighed and incinerated completely, the loss of weight giving the percentage of fiber.

Ash.- Some of these determinations were made by burning a weighed portion of the substance in a platinum boat inside a glass tube, through which a current of oxygen was passing; it was, however, found that satisfactory results could be obtained by incinerating in a platinum crucible; exhaustion with water was not required.

Cellulose.-This cletermination was made by means of the potassium chlorate method originally suggested by F. Schulze. ${ }^{1}$ From 2 to 6 grams of the powdered substance were digested with I2 parts of nitric acid (sp. gr. I.IO) and 0.8 part of potassium chlorate in a closed flask, and kept for about a fortnight at a temperature below $15^{\circ}$. Distilled water was then added and the liquid siphoned off; the residue was washed into a beaker with dilute ammonia (I part strong ammonia to 50 of water) and heated for about forty-five minutes at $60^{\circ}$; next the residue was thrown on a weighed filter and washed with the dilute ammonia till the filtrate was colorless; it was then washed successively with cold and with hot water. alcohol and ether: it was finally

1 Chem, Centrbt, Is:7, p. 321 . 
dried and weighed. Any nitrogenous matter present was estimated by Kjeldahl's method, and ash by ignition.

Nitrogen.-Kjeldahl's method, modified to include the nitrogen of nitrates, as given in Bulletin 46, U. S. Department of Agriculture, Division of Chemistry, was used in the determination of nitrogen. At least three estimations were made.

Protein.-The protein was calculated by multiplying by 6.25 the nitrogen, as before determined by Kjeldahl's method.

Starch or Carbohydrates by Direct Inversion with Hydrochloric Acid.-The starch was indirectly determined by inversion into glucose. In former investigations with vegetables ${ }^{1}$ the usual method given in text-books was employed, but, on titrating with Fehling's solution, in the case of green vegetables, a blue or white precipitate came down. A modification of the method was tried and proved successful, and was therefore employed in this set of investigations. Solutions were prepared as suggested by Sachsse. ${ }^{2}$ A weighed portion of the vegetable powders was digested with Io cc. of hydrochloric acid (sp. gr. I.I25) and I0O cc. of water, in a flask connected with a reflex condenser; the whole was briskly boiled for three hours, and the solution filtered. Instead of neutralizing with sodium hydroxide, the filtrate was treated with basic acetate of lead, and a current of sulphur dioxide was passed through the liquid to precipitate any excess of lead present. The solution was filtered and washed, and alumina was added until no more was dissolved; it was concentrated at $100^{\circ}$ and, when necessary, boiled with animal charcoal and a few drops of milk of lime, and finally filtered before titrating with Fehling's solution; the latter was prepared according to the usual method, and standardized by the directions given by Roscoe and Schorlemmer in the "Treatise on Chemistry."3 Each cubic centimeter of Fehling's solution was calculated as equivalent to 0.05 gram of anhydrous glucose, or 0.045 gram of starch.

Sulphur and Phosphorus.-These estimations were made by fusion with mixtures of sodium carbonate and potassium nitrate; the sulphur was determined as barium sulphate, and the phosphorus precipitated as magnesium ammonium phosphate, which was dissolved in a solution of acetic acid, reprecipitated,

1 Trans. Chem. Soc. (London), I892, p. 236.

2 Chem. Centrbl., 8, 639 and 732.

vol. III, Part 2, p. 519. 
and ignited; the percentage was calculated from the pyrophosphate after ignition.

As stated in the beginning of this paper, the work described was unclertaken with the idea of arriving at a clearer knowledge of the composition of vegetable foods as served at table. It is difficult to compare the results obtained with those of other investigators, for even in the raw condition great differences in composition occur, and the differences are necessarily greater after cooling. It may be noticed that almost all the vegetable substances become more watery in the process of cooking, the exceptions being broccoli, where the weight of the raw and cooked conditions is practically the same, while in the case of asparagus a consiclerable decrease of weight takes place in the process of cooking, due probably to the loss of soluble nitrogenous compounds; this latter article of food is rendered expensive by its large percentage of waste, both before and after cooking. With regard to the green artichokes, it may be pointed out that in the raw condition this is a somewhat tough vegetable, and in the process of cooking absorbs a larger proportion of water than the other green vegetables. It will be observed from the details given that the liquor in which all the foods were cooked, except in the case of oatmeal and tapioca, was poured off, and thus, as shown in Bulletin 43, U. S. Department of Agriculture, all matter in solution is lost; "as ordinarily cooked, carrots lose one-quarter of their nutritive value." "In Ioo pounds of uncooked cabbage there are but $71 / 2$ pounds of dry matter, and of this dry matter $21 / 4$ to 3 pounds are lost in the process of cooking."

Table II gives full details of the analysis of the dried, powdered vegetable foods, showing the percentages of ash, protein (calculated from nitrogen), woody fiber, fats, and cellulose, the starch by difference, also by inversion, a column headed undetermined being added to bring the total results up to 100 in the latter case. Ultimate analyses are also given for the nitrogen, phosphorus and sulphur.

Table III gives the proximate analyses calculated on the materials in their natural moist condition, in order to more clearly show the true nutritive value of the foods under consideration. 


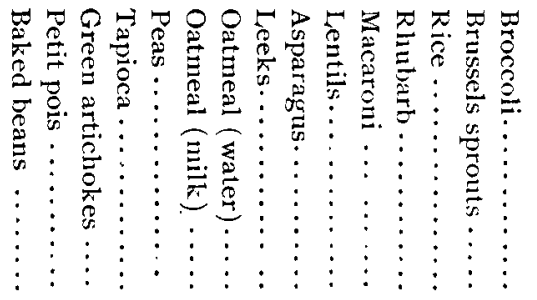

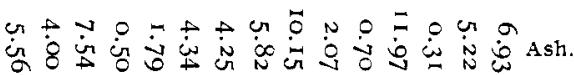

in

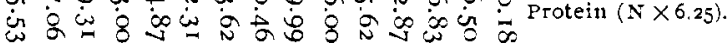

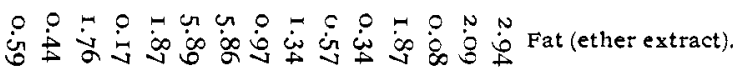

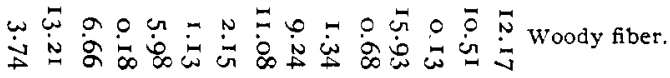

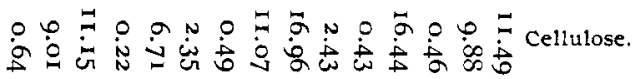

Яㄷํㅇ

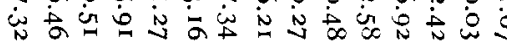

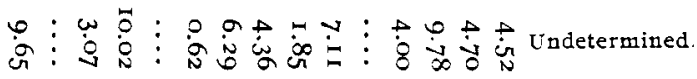

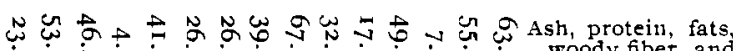

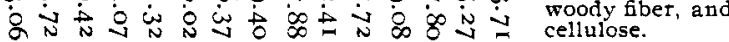

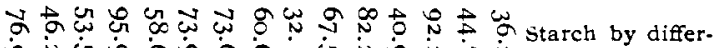

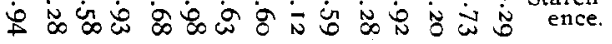

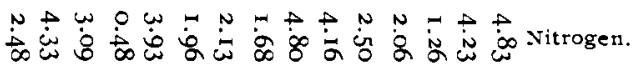

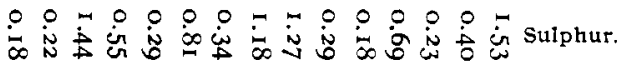

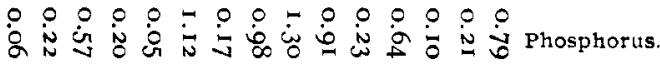


TABLE III.-Proximate ANalysis Calculated for the Materials in Their Natural Moist Condition.

\begin{tabular}{|c|c|c|c|c|c|c|c|c|c|}
\hline \begin{tabular}{l}
$\bar{\Xi}$ \\
\multirow{2}{*}{}
\end{tabular} & $\frac{5}{30}$ & 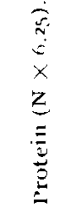 & 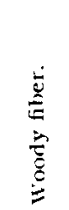 & $\stackrel{3}{3}$ & $\stackrel{\dot{x}}{\vec{x}}$ & $\frac{\dot{J}}{\stackrel{5}{5}}$ & 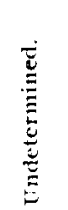 & 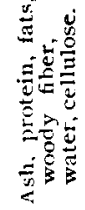 & 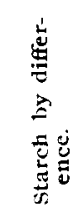 \\
\hline roccoli........ 91.69 & $0.5^{8}$ & 2.53 & 1.02 & 0.96 & 0.24 & 2.63 & 0.60 & 96.77 & 3.23 \\
\hline uts. . 89.27 & 0.56 & 2.84 & I. 12 & 1.05 & 0.07 & 4.29 & 0.80 & 94.91 & 5.09 \\
\hline$\ldots \ldots \ldots 80.93$ & 0.06 & 0.13 & 0.02 & 0.09 & $0.0 \mathrm{I}$ & 16.87 & 0.89 & 82.24 & 17.76 \\
\hline b....... 95.25 & 0.56 & $0.6 \mathrm{r}$ & 0.75 & 0.77 & 0.09 & I.74 & 0.23 & 98.03 & 1.97 \\
\hline ......666.13 & 0.23 & 5.59 & 0.23 & 0.14 & $0 . \mathrm{II}$ & 27.90 & $\ldots$ & 72.43 & 27.57 \\
\hline$\ldots \ldots \ldots 66.04$ & 0.70 & 8.82 & 0.45 & 0.82 & 0.19 & 20.53 & 2.45 & 02 & 22.98 \\
\hline gus....... 93.04 & 0.70 & 2.08 & 0.64 & I. I 8 & 0.09 & 2.10 & 0.17 & 97.73 & 2.27 \\
\hline ...... 86.12 & 0.80 & I. 45 & 1.53 & 1.52 & 0.13 & 7.80 & 0.65 & $9 \mathrm{I} \cdot 55$ & 8.45 \\
\hline water) .72 .54 & I. 16 & 3.74 & 0.59 & 0.13 & I. 84 & 18.48 & 1.72 & 79.80 & 20.20 \\
\hline$(\operatorname{milk}) \ldots 64.74$ & I. 55 & 4.39 & 0.40 & 0.84 & 2.10 & $25 \cdot 96$ & 0.02 & 74.02 & 25.98 \\
\hline$\ldots \ldots \ldots 62.18$ & 0.67 & 9.40 & $2.2 \mathrm{I}$ & 2.53 & 0.70 & 23.16 & $\cdots$ & 77.69 & $22.3 \mathrm{I}$ \\
\hline ....8 80.62 & 0.09 & $0.5^{8}$ & 0.03 & 0.04 & 0.03 & I 6.65 & 3.55 & 79.80 & 20.20 \\
\hline chokes.. 84.72 & 1.15 & 2.95 & $1.0 \mathrm{I}$ & 1.70 & 0.26 & 7.68 & 0.53 & 91.79 & 8.21 \\
\hline$s \ldots \ldots \ldots 84.18$ & 0.6 .3 & 4.28 & 2.13 & 1.42 & 0.06 & 8.92 & $\cdots$ & 92.70 & $7 \cdot 30$ \\
\hline Baked beans.....6.69.85 & 1.78 & & 1.20 & 0.20 & 0.19 & 21.69 & 2.10 & 76.21 & 23.79 \\
\hline
\end{tabular}

\title{
INVESTIGATION OF THE BODIES CALLED FIBER AND CARBOHYDRATES IN FEEDING-STUFFS, WITH A TENTATIVE DETERMINATION OF THE COMPONENTS OF EACH. ${ }^{1}$
}

\author{
BY P. SCHWEITZER.
}

Received December 30, z903.

THE results of a continuation and extension of the work of which a preliminary part was published in the Annual Report of the Missouri Agr. Expt. Station for 1898 are here presented. Ten substances-two of corn stalks, two of corn leaves, three of timothy hay, two of red clover, and one of blue grass-were selected for the purpose. The character and composition of these, as ascertained by the Official Agricultural Chemists' method, all determinations being in duplicate and made with great care under conditions as nearly alike for the same groups of bodies

1 Read at the St. Louis meeting of the American Chemical Society. The larger part of the laboratory work was done by Mr. W. B. Cady. 